\title{
The Contribution of Emotional Intelligence to Human Resource Development and Career Success: A Review
}

\section{Ana Chagelishvili}

PhD Candidate, Ivane Javakhishvili Tbilisi State University, Faculty of Economics and Business, Tbilisi, Georgia

\section{Abstract}

This paper is the review of the main scientific literature about the role of emotional intelligence in career success and human resource development. It aims to analyze how emotional intelligence and its components determine human resource development or career success. Through documentary analysis the paper is based on reviewing leading scientific publications and summarizes main theoretical approaches. The results of the analyze show that emotional intelligence helps employees in many ways to achieve success at work and also highlight the need for more attention to the development of employees' emotional intelligence in organizations. The review also addresses promotion issues which consideration will avoid organizations further problems. This analysis will be especially useful for managers to improve the quality of employees' performance. This review on emotional intelligence issues in terms of career success contributes to review literature about human resource management and development and it may also indicate future directions for surveys.

Keywords: emotional intelligence, career success, human resource development

\section{Introduction}

During a lifetime, emotions determine a person's motivation, decisions and actions in personal relationships or at work. Due to such a power, emotions directly or indirectly determine a person's success. Regarding this, researchers have concluded that career success need to be discussed by extrinsic and intrinsic factors (Spurk, Hirschi, Dries, 2019: 35-69).

In organizational activities, a person has to be a participant in social relations, realizes his/her skills and knowledge, develops and gains new work experiences, achieves goals, advances on the path of career development. During this work life business environment is full of challenges, responsibilities, stress, difficulties or even failures. People have feelings and express emotions constantly, however, there is less of observation and thinking about them. Immature and uncontrollable emotions can 
even be the beginning of a number of destructive actions. At first glance, emotionality is perceived as a weakness at work, however, not the emotions themselves, but the emotion-thoughts-action process determines the successful or unsuccessful job performance. Nowadays stressful work environment and problems complicate to transform emotions into the right decisions, under which emotional intelligence has become even more important at work.

Emotional intelligence has always been contributed in human success, and its increasing popularity does not mean that it has become necessary only now. Reality has made it clear that strengthening the idea of a perfect employee in a modern, global, rapidly changeable and stressful work environment with technical knowledge and a high IQ (intelligence quotient) only is not enough. Consequently, scientific researches about emotional intelligence issues had begun and nowadays organizations pay attention to it in a frame of employee development. Emotional intelligence has an affect on communications and all areas where social relationships are crucial to success. In view of aforementioned, the study of emotional intelligence issues in the work environment and its role in career development are undoubtedly relevant, interesting and practical.

The organizational progress leads to the development of human resources and vice versa. Nowadays, organizational success is unreal without strong partnerships and without satisfied customers, and internally without harmonious, collaborative work of employees. A prerequisite for all this, among other important issues, are people with high emotional intelligence, technical skills, as well as high IQ. The aim of the research is to study well-known and recent researches and find out how emotional intelligence is realized in issues that contribute in human resource development and career success.

The results of the research have practical value for employees and managers, as well as for all interested people who work in social environment. From a scientific point of view, the paper contributes to the management field and development of human resources, also, it provides a basis for further research. In the future, the range of issues in which emotional intelligence is realized and how the career success of an employee is determined may be explored and enhanced.

\section{Methodology}

The general objective of this research is to examine the published scientific literature about emotional intelligence contribution in human resource development and on career success. To achieve objectives, the research proceeds through a qualitative approach with a systematic literature review-SLR design (Fink, 1998; Soaita, Serin, Preece, 2019: 1-24). At first, the following selection criteria were defined:

1. Harvard Business Review is the main database selected for research, with a number of well-known authors articles about emotional intelligence and human resource development. 
2. Besides, different scientific databases were chosen for the research. Within the search characteristics, 3 word combinations were taken into account: Emotional Intelligence; Human Resource Development and Career Success. The search was carried out without a date limit and as for the type of documentation, articles, conferences-proceedings- and books were included.

Over 100 manuscripts were obtained from which 2 analysis criteria were applied:

1. Human resource development was considered only in terms of employees.

2. Emotional intelligence was considered only in terms of human recource development and career success.

\section{The Essence of Emotional Intelligence}

From the $1^{\text {th }}$ century the interest in emotional intelligence was becoming stronger. Initially, its ideology originated with the concept of social intelligence (Thorndike, 1920: 227-235), then transformed into the term emotional strength and now it has formed as the subject of researches with the name of emotional intelligence.

Many authors interpret the essence of emotional intelligence differently according to the different theories. In the future it may lead to an excess of terms and cause confusion. In general, it can be said that emotional intelligence is the ability to understand and manage one's own and others' feelings (Alsughayir, 2021: 13101311). Since the last century, many authors have written papers on a number of issues of emotional intelligence and have begun to focus on it in terms of human resource management, however, the main practical value of emotional intelligence is success in social relationships or careers.

Daniel Goleman, who contributed greatly to the scientific research of emotional intelligence, in the last century focused on a bizarre fact: how it happened that some talented people were unsuccessful in their work, and some less talented employee were quite successful in their career. After have done 188 company competency model analysis, he named emotional intelligence as the reason for such strangeness, and it was completely different from cognitive and technical skills. It should be noted that Goleman was not denying the necessity of intellect and technical skills for the success, however, he presented them as an incomplete set of success without emotional intelligence (Goleman, 2004: 82-91). H. Gardner has a similar view. According to the theory of multiple intelligences, the author supports the fact that a high IQ alone is not sufficient for success (Gardner, 2011).

According to Goleman, learnable emotional intelligence combines 5 components: selfawareness, self-regulation, motivation, empathy, and social skill. As the author divides, the first three components are self-management skills, while the last two are relationship management skills. Often, a number of reasons lead to an inadequate 
perception of a person's inner and outer world, simply put, insincerity to oneself. Therefore, self-awareness is revealed and achieved only when a person evaluates himself realistically and sincerely. In self-awareness, Goleman considers understanding one's own values and goals first. Goleman characterizes selfregulation as the liberation from the captivity of one's own feelings and compares to a "ongoing inner conversation." Self-regulation involves directing emotions in useful activities. Its productivity is manifested in the fact that instead of panic, people are able to make and adapt rational decisions. Goleman also notes that often, people with self-regulatory ability are perceived as insensitive people, however, based on research, he concludes the ineffectiveness of extreme manifestations of emotion (Goleman, 2004: 82-91). If we go deeper, the management of one's own emotions implies the existence of a controlling object, or feelings, which is logically contrary to the view that people with self-regulation are devoid of feelings.

Regardless of emotional intelligence, motivation is also considered to be one of the main characteristics of a leader. According to Goleman, emotional intellectual motivation arises not only for the sake of status and salary, but also, motivation is directed towards achievements. As for empathy, which may sound irrelevant for business, Goleman describes it as an in-depth understanding of employee's feelings in the decision-making process. The role of empathy is especially evident in teamwork, where it is difficult to reconcile emotions and thoughts of all members. The importance of empathy for a leader is also increased by the pace of globalization and cross-cultural relationships, when empathetic employees need to pay attention to even the smallest nuances. Since a simple definition of social skill does not exhaust the essence, Goleman offers a description of it. He describes that a person with social skills has a wide circle of acquaintances, can find common ground with any type of person and have a good ability to persuade. In the workplace, people with social skills may seem less hard-working, however, Goleman sees social skills as the basis of a leader's main task of doing the job through other people (Goleman, 2004: 82-91).

\section{Emotional Intelligence at Work}

Development and success for the employees who is not satisfied with their job is almost unrealistic. High emotional intelligence determines job satisfaction to some extent, after that employees begin developing and succeeding (Goleman, 1998; Kafetsios, Zampetakis, 2008: 712-722; Yuan, Tan, Huang, Zou, 2014: 1057-1068; Miao, Humphrey, Qian, 2017: 177-202; Urquijo, Extremera, Azanza, 2019: 4809). Selfawareness helps a person to understand aspirations, field of desired job and values. As a result, a person seeks and starts a professional career in a desired job, which is accompanied by a high level of job satisfaction. Job satisfaction in turn lays the foundation for development and success.

Job satisfaction is related to employee productivity. It directly or indirectly contributes to the success not only of the organization but also of the employees. Productivity is determined by many factors, among which are the inner state of a 
person, visions and attitudes (Kharkheli, Morchiladze, 2016: 618-619). An emotionally intelligent person clarifies his inner state through self-awareness, after that certain visions emerge and attitudes are formed. An essential prerequisite for productivity is employee purposefulness. Going towards the goal, the desire and effort to do the job best is nothing but motivation, which is the compiler of emotional intelligence as well.

Both, job satisfaction and productivity are typical of standard workflows. Often, professional or personal development means overcoming difficulties and thus learning. What if a person meets certain obstacles, stress, or failures on the way to success? How valuable would knowledge, experience, or talent can be if a person simply could not withstand such difficulties? Nowadays, in stressful, fast-changing, and unexpected world, such difficulties are not uncommon. On the one hand, motivation may play a major role in dealing with difficulties, however, motivation only is not enough to keep moving forward, employees need more - the ability to respond to external factors, but not in a way that destroys a person from emotion. Diane L. Coutu names that such ability is human resilience. In a view of ethics, the author does not consider the concept of resilience in positive or negative contexts. She sees it as the ability to maintain resilience under the high stress. She points out that according to almost all theories of resilience, there are 3 characteristic aspects of a resilient person: 1 . Acceptance of reality; 2 . A deep belief that life is meaningful. Such attitudes are often driven by rigid values and 3. the ability to improvise (Coutu, 2002: 46-51).

In order for a person to be able to manage something, it is necessary to give a name to a control object, which means to know the essence. Accepting reality is nothing more than self-awareness and empathy. Coutu notes that because the existence of meaning thus determines the resilience of people, it is not surprising that organizations have solid value systems: "Strong values infuse an environment with meaning because they offer ways to interpret and shape events" (Coutu, 2002: 4651).

Important issues of meaning therapy are discussed by psychiatrist Victor E. Frankl, in his book Man's Search for Meaning. The issues are directly related to resilience and emphasizes that one should not lose the meaning of life even in a seemingly completely hopeless situation (Frankl, 1992: 45-50).

As for the third component of resilience - the ability to improvise, Coutu describes it as "the ability to make do with whatever is at hand". She points out that resilience may be based on human optimism, however, as long as it maintains a perception of reality. Coutu emphasizes that the main challenge when talking about resilience may be its unstable nature. It implies that showing resilience in one situation does not mean having the same ability in other difficult situations (Coutu, 2002: 46-51). Similarly, to this reasoning, although emotional intelligence is a consistently characteristic feature of a person, it does not imply the infallibility of the individual 
in making all decisions and by the equal activity level of the components of emotional intelligence.

In a work environment full of problems and stress, the flow of negative thoughts and emotions further complicates the situation, which may lead to negative consequences for organizations. Instead of succumbing to emotions or expelling thoughts, emotionally intelligent people are able to manage wisely, which David and Congleton call emotional agility. The authors highlight 4 practical steps adapted from acceptance and commitment therapy to manage this negative process and achieve a positive outcome, which were originally developed by Stephen S. Hayes: 1. Recognizing and understanding pattern); 2. Label thoughts and emotions; 3. Accept thoughts and emotions; 4. Act on values (Hayes, 2004: 639-665; Congleton, 2013: 125-128).

In a stressful situation, it becomes especially important to regulate emotions, which then becomes the basis for an effective decision. Stress management through emotional intelligence is thought to the management of own emotions to alleviate or avoid the negative effects of stress. Adaptation in a stressful situation means accepting and adapting to changed circumstances.

Conflicts and controversies in an organization are similar to stressful situations, which hinder the proper functioning of the system and which is undoubtedly a significant issue for organizations. Conflicting, non-teamworking and lacking social skills employees rarely if ever succeed. In exceptional cases, it is demotivating for employees to be subordinated for such a person, and his or her leadership is generally in question. That is why the importance of emotional intelligence is huge for both inside and outside the organization, for satisfied customers or for establishing winwin relationships with partners.

How does emotional intelligence handle conflicts? The best answer to this question would probably be conflict prevention. Neutralizing the very embryo of conflict requires much more effort and skill than it may seem at first glance. Self-regulation, which protects a person from emotional outbursts, will inevitably weaken the escalation of conflicts, motivate efforts to resolve problems, while empathy towards conflict party and social skills will facilitate the achievement of the set goals.

A sense of humor may be attributed to socio-emotional competence. Its rational use is of great importance in both non-conflict and conflict situations and is often very effective in preventing escalation. Emotional intellectual humor often relieves tension and reduces the negative impact of stress on the person, while in a normal situation it promotes the formation of benevolent social relationships. However, it is also noteworthy that humor can often have a negative impact on relationships and can be transformed into destructive forms such as sarcasm, manipulation, ridicule, insults, irritability and etc. (Nikic, Travica, Mitrovic, 2014: 281-292).

Development and success depend on internal processes, especially thinking and attitudes. According to psychologist Carol Dweck, people may be grouped into two 
contrasting groups based on their attitudes and thinking. Some are distinguished by unchanging thinking, perceive the environment as a given, and even small inconsistencies have a destructive effect on them. The second group is distinguished by a growing mindset, perceive change as a challenge, and address their growth and development. Exactly the last kind of employees achieve great career success than the first category of people, who may have possessed more intelligence (Dweck, 2006).

In an age of changes and innovations, the organization must also be flexible to the challenges of the environment. The same is required of the people who make up the organization. Growing, developing thinking and adaptability to innovations are undoubtedly of great value of employees, however, everything is necessary in parallel with the development of emotional and cognitive intelligence. The growth of thinking means personal growth, which is unreachable without the development of emotional intelligence.

"Success" can not always be successful. It is often the case when organizations promote talented, active and hardworking employees to higher hierarchical levels. After a certain period of time, the decisions made by them do not turn out to be so right, for which employee itself, the organization and even the consumer pay the price. The issues of such a paradox were explored by Bunker, Kram and Ting. The authors point out that it is erroneous to promote premature and ambitious top personnel with great potential, because they may do not have developed the most important aspects of emotional intelligence, which is a vital precondition for their career advancement (Bunker, Kram, Ting, 2002: 80-87). In the end, it turns out that speed is a waste of great potential.

If career advancement turns out to be timely, a much higher level of emotional intelligence will be required for further success. Interestingly, Goleman concludes that the higher a person's position in an organization, the greater the share of emotional intelligence in the effectiveness of his/her activities. In other words, emotional intelligence plays an increasingly important role for those working at the highest hierarchical levels of the organization for the best results of success and performance. Hence, it is logical to conclude that the concept of emotional intelligence is undoubtedly important for the characteristics of a leader (Goleman, 2004: 82-91). A major determinant of the need for emotional intelligence in activities at a high hierarchical level is an increase in the frequency of social interactions. Researches have shown similar results and have shown that managers, including those at a higher hierarchical level, have a better sense of humor, more satisfaction with life, and more social activity (Nikic, Travica, Mitrovic, 2014: 281-292).

Numerous studies confirm the importance of emotional intelligence in successful and transformational leadership (Hajncl, Vučenović, 2020: 119-129). Emotional competence directly determines the effectiveness of both general and team management (Kunalić, Mujkić, Jusić, Pajević, Rovčanin, 2016: 297-310). Because leadership is about motivate other people to work more effectively, it is emotional 
competence that plays a major role in this process. It may even be unrealistic that a leader could properly manage others without the ability of social relationships (Kharkheli, Morchiladze, 2016: 618-619).

Regression analysis has shown that emotional intelligence not only as a whole, but also its constituents individually determine the effectiveness of management (Saddiqui, Jawad, Naz, Niazi, 2018: 99-130). At the hierarchical level, empathy plays one of the key roles in achieving success. It is empathy that helps a leader influence employee by understanding and sharing his/her emotional state. Nicholas Epley has discussed this view in his book Mind wise: How We Understand What Others Think, Believe, Feel, and Want. He writes the extent to which the ability of empathy determines the success of leaders themselves. It is empathy that helps managers understand the needs and desires of employees, after which they are given the opportunity to motivate them (Epley, 2014).

What does it mean to use empathy skills at work? The answer cannot be simple and unambiguous, because empathy manifests itself in different ways in different situations. It can be observing anything while listening to a person, understanding in a certain situation or just solve others problem. For an emotionally intelligent person, empathy dictates the algorithm of action itself.

One of the most important issues in the study of emotional intelligence is the influence of leader's emotional style. Mood swings are a real neurological phenomenon in humans, as confirmed by numerous psychological and physiological studies. Goleman, Boyatsis, and McKee point out that a leader's mood has a huge impact on a job performance quality, because it governs the behavior of all other employees. The authors describe emotional intelligence providers in relation to leader's mood and the ideal leader as follows: An emotionally intelligent leader, through self-awareness, can track his own mood, use self-control to change for the better, empathize - understand his influence, and manage relationships to improve the mood of others (Goleman, Boyatzis, McKee, 2001: 42-51). It should be noted that the development of leadership in the organization in some way contributes to maintaining a balance between family and career, which is confirmed by researches (Pirtskhalaishvili, Faresashvili, Kulinich, 2021: 261) and which in some respects is achieved through high emotional intelligence.

\section{Results and Conclusion}

The number of papers selected according to the criteria from the retrieved publications reached about $80 \%$. In conclusion, we can say that emotional intelligence contributes to the development and success of a person through different activities at different stages of career development. Initially, it may be intellectual abilities that will lead to career advancement, however, in the long run, emotional intelligence will play a much bigger role in career advancement. In this regard, for future success it is important for a person to realize the importance of a particular 
skill at a particular stage and to improve their emotional intelligence level through some kind of emotional training.

Development and success are largely based on job satisfaction, on which a career must be built. Even in stressful and conflict situations, emotional intelligence takes the form of resilience and does not lose meaning, which determines future vitality. A great deal of importance is attached to the sense of humor in defusing tense situations, however, transforming it into a destructive form is dangerous. As a recommendation, it can be said that it is important for a person to define his / her personal or professional values and values in a normal and quiet business period, in order to help him / her overcome difficulties in a difficult situation in the future. Along with meaning, it is important to show resilience, which is stronger the stronger and clearer the meaning of personality.

Emotional intelligence issues also consider growing thinking and rational attitudes that can contribute to a person's future success. Growing thinking is in some ways also a teacher of personality development. A key issue is the timeliness of career advancement, where speed can be devastating even in the long run. The reason for all this may be the fact that career advancement requires more and more developed emotional intelligence.

Finally, a high level of emotional intelligence, or even its constituents individually, may be a kind of example and contagious phenomenon for other employees: the emotional style of management spreads throughout the team, the motivation of the leader also becomes a motivator for subordinates, and so on.

\section{References}

[1] Alsughayir, A. (2021). The effect of emotional intelligence on organizational commitment: Understanding the mediating role of job satisfaction. J.: „Management Science Letters“, Vol.11, No.4, pg: 1310-1311.

[2] Coutu D. L. (2002). How Resilience Works. J.: „Harvard Business Review“. Vol.80, No.5, pg: 46-51.

[3] David S., Congleton C. (2013). Emotional Agility. J.: „Harvard Business Review“. Vol.91, No.11, pg: 125-128.

[4] Dweck, C. S. (2006). Mindset: The new psychology of success, New York: Random House.

[5] Epley, N. (2014). Mindwise: Why We Misunderstand What Others Think, Believe, Feel, and Want. New York City, Knopf.

[6] Fink, A. (1998). Conducting literature research reviews: from paper to the Internet. Sage.

[7] Frankl V. E. (1992). Man's search for meaning: an introduction to logotherapy. „Beacon Press“, 4th edition, pg: 45-50.

[8] Gardner, H. (2011). Frames of mind: The theory of multiple intelligences. New York: Basic Books, 10th edition. 
[9] Goleman D., Boyatzis R., McKee A. (2001). Primal leadership: The hidden driver of great performance. Harvard business review, Vol.79, No.11, pg: 4251.

[10] Goleman, D. (1998). Working with emotional intelligence. Bantam Books.

[11] Goleman, D. (2004). What Makes a Leader? Harvard Business Review, Vol.82, pg: 82-91.

[12] Hajncl L. (2020). Vučenović D. Effects of Measures of Emotional Intelligence on the Relationship between Emotional Intelligence and Transformational Leadership. J.: „Psihologijske teme“, Vol.29, No.1, pg: 119-129.

[13] Hayes, S. C. (2004). Acceptance and commitment therapy, relational frame theory, and the third wave of behavior therapy. J.: „Behavior Therapy“, Vol.35, pg: 639-665.

[14] Kafetsios K., Zampetakis L.A. (2008). Emotional intelligence and job satisfaction: Testing the mediatory role of positive and negative affect at work. Personal. Individ. Differ, Vol.44, pg: 712-722.

[15] Kerry A. Bunker, Kathy E. Kram, and Sharon Ting. (2002). The Young and the Clueless, Harvard Business Review, Vol.80, No.12, pg: 80-87.

[16] Kharkheli M., Morchiladze G. (2016). Importance of development emotional intelligence, The International Scientific Conference "Challenges of Globalization In Economics And Business “, Universali, pg: 618-619.

[17] Kunalić, B., Mujkić, A., Jusić, J., Pajević, M. \& Rovčanin, Dž. (2016). Impact Of Emotional Intelligence On Leader Effectiveness. J.: „Ekonomski vjesnik“, Vol.29, No.2, pg: 297-310.

[18] Miao C., Humphrey R.H., Qian S. (2017). A meta-analysis of emotional intelligence effects on job satisfaction mediated by job resources, and a test of moderators. J.: "Journal of Occupational and Organizational Psychology", Vol.90, No.2, pg: 177-202.

[19] Nikic, G., Travica,V., Mitrovic, M. (2014). Differences Between Employees And Managers Regarding Socio-Emotional Competencies. J.: „Serbian Journal of Management", Vol.9, No.2, pg: 281-292.

[20] Pirtskhalaishvili, D., Paresashvili, N., \& Kulinich, T. (2021). The gender aspects of career development and leadership in organizations. Journal of Eastern European and Central Asian Research (JEECAR), 8(2), 255 - 266.

[21] Saddiqui, S.A., Jawad, M., Naz, M. \& Niazi, G.S.K. (2018). Emotional Intelligence And Managerial Effectiveness. J.: „Review Of Innovation and Competitiveness", Vol.4, No.1, pg: 99-130.

[22] Spurk D., Hirschi A., Dries N. (2019). Antecedents and outcomes of objective versus subjective career success: competing perspectives and future directions. J.: „Journal of Management", Vol.45, No.1, pg: 35-69.

[23] Soaita, A. M., Serin, B., Preece, J. (2019). A methodological quest for systematic literature mapping. J.: „International Journal of Housing Policy“, pg. 1-24.

[24] Thorndike, E. L. (1920). Intelligence and its uses. Harper's Magazine, Vol.140, No.1, pg: 227-235. 
[25] Urquijo, I., Extremera, N., \& Azanza, G. (2019). The Contribution of Emotional Intelligence to Career Success: Beyond Personality Traits. J.: „International journal of environmental research and public health“, Vol.16, No.23, pg: 4809.

[26] Yuan L., Tan X., Huang C., Zou F. (2014). mediating effect of job satisfaction on the relationship between emotional intelligence and perceived general health. J.: „Social Behavior and Personality: An international journal“, Vol.42, No.7, pg: 1057-1068. 